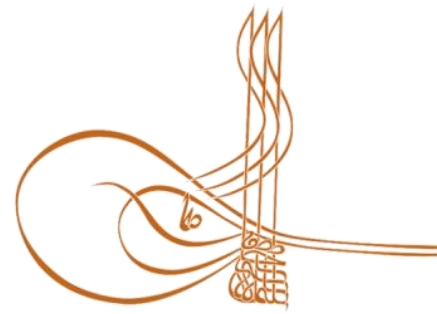

www.turkishstudies.net/economy
Turkish Studies - Economics, Finance, Politics

eISSN: $2667-5625$

Research Article / Araștırma Makalesi

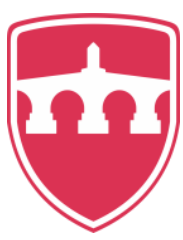

INTERNATIONAL BALKAN

UNIVERSITY

Sponsored by IBU

\title{
Duygulardan Arındırılmış Yatırım Yöntemi “Algoritmik Alım-Satım” Üzerine Genel Değerlendirme ve Örnek Algoritma Çalışması
}

\author{
General Evaluation on Non-Emotional Investment Method "Algorithmic Trading” and Sample of \\ Algorithm Study
}

\author{
Fatih Altındiș*
}

\begin{abstract}
Nowadays, it is not possible to think that the capital markets will stay away from technological impact, as technology has intensely felt itself in every aspect of our lives. In this sense, the fact that automation and new technologies have increased exponentially over the past ten years has led to the technological evolution of the capital markets. Technological improvements contains a whole range of improvements and modifications that can feed off individual investors as well as institutional investors and professional traders. For the time being, the majority of trading transactions are made by algorithms. The diversification of the factors affecting the price changes of financial instruments, the complexity of the market conditions, the less profitable of the markets which is compared with the past and the most importantly, the speed of market movements due to the developing communication opportunities and the fact that this factor of speed surpasses the most expectations made it necessary to use the algorithm in the capital markets. Whether the algorithms created according to the classical technical analysis methods or the algorithms which have been created with the increasing artificial intelligence methods recently, it is obvious that all these have increased in weight to direct the money movements. While this development in the capital markets offers many opportunities for investors, on the other hand, it contains many threats. The aim of this study is to make a general evaluation and to gain perspective for investors about the algorithms which have been in use in the developed markets for a long time but which have been in the agenda of the capital market in our country recently, which has a great interest for investors.
\end{abstract}

Structured Abstract: This study tries to measure the performance of the market with a mathematical algorithm designed as an example by giving general information to the investors and researchers on the subject of automatic trading through algorithms in financial markets, which are also widespread in our country in parallel with the technological developments. In the preparation of the study, especially the increase of this new trading discipline in the capital markets of our country in parallel with Europe, especially the USA, was effective.

In the first part of the study, the relationship between algorithm and finance and the advantages and disadvantages of using algorithms are examined. In this sense, it has been seen in the literature that the

\footnotetext{
* Bilim Uzmanı, Meksa Yatırım

Graduate

ORCID 0000-0002-6470-9014
}

fatihaltindis@hotmail.com

Cite as/ Attf: Altındiş, F. (2020). General evaluation on non-emotional investment method "algorithmic trading" and sample of algorithm study, Turkish Studies - Economy, 15(1), 23-34. https://dx.doi.org/10.29228/TurkishStudies.37827

Received/Geliş: 26 September/Eylül 2019

Accepted/Kabul: 25 March/Mart 2020

Copyright (C) INTAC LTD, Turkey 
algorithmic transaction is defined as the transmission of the trade to the market through computers. (Chan, 2009). It is also stated that this new discipline is known by names such as robo trading and black box trading (Kissell, 2014 ; Kim, 2007). In addition to that, it has been observed that the share of algorithmic transactions in total transaction volume is increasing day by day and has become an important part of the modern financial market (Kim, 2007 ; Kissell, 2014 ).

In the second part, it is discussed that the use of the algorithm in the financial markets, which is increasingly used, has advantages and disadvantages for investors. In this sense, it is seen as the most obvious advantage of the algorithms that it offers the opportunity to perform fast processing without being exposed to psychological factors, on the othe hand, the possibility of poorly constructed algorithms having the potential to cause serious damage and the possibility of different algorithms triggering each other and causing hard movements are seen as disadvantages of the use of the algorithm.

However, in terms of the development of algorithm use, it has been determined that there has been a cumulative 10.3\% increase in the last 20 years (Technavio's 2016 raporu : Global Algorithmic Trading Market, 2016-2020). It can be shown for increasing usage of algoithm that they are easy to use, facilitate decision making, high speed, reduce human errors and affordable cost.

In the third section, general algorithm types are examined and it is tried to make it easier for investors and researchers to choose the appropriate algorithm type for them. For example, investors who want to take advantage of the intraday price movements may prefer intraday algorithms. As the intraday trading algorithms perform excessive transactions, investors will pay extra trading commissions, but they will also be protected from developments that will reverse their positions at times when the market is closed. In addition, investors who want to pursue trends will be able to earn high profits by taking advantage of large price movements if they are in the right direction, but they will not be protected from the developments against their positions during the hours when the market is closed. Speed-oriented investors who want to take advantage of the arbitrage opportunities or who want to sell their large amount of stock by dividing them into small pieces will be able to invest using HFT algorithms.

In the last section, how to design an exemplary strategy has been studied and a trend algorithm has been constructed and its performance has been tested on the past 10 years of VIOP30 data and it has been measured how a emotion-free method has performed. Some technical indicators and price data were used while designing the sample algorithm. Especially the ratios explained in the performance evaluation of the algorithm will provide ease in measuring the quality of the algorithm. In this sense, ratios such as monthly average net profit, earning rate, average profitable transaction, average of harmful transaction, profitability rate, profit and profit rate per transaction are explained through the sample algorithm.

In this sense, an algorithm has been created using Alligator indicators, Parabolic SAR, Aroon Oscillator and 10-year period high and low prices. The created algorithm was tested in 5-minute data periods between 01.01.2010-31.12.2019. As a result of this test, the algorithm performed 1162 transactions in the specified date range and achieved a gross profit of 250,050 points. $42 \%$ of the transactions were profitable and the rest resulted in loss. However, since the profit points of the transactions that result in profit are higher than the profit points of the transactions that result in loss, the grand total has resulted in profit. In addition, when looking at the total amount of months, $62 \%$ of the period of the months were resulted in profit. As a result of the test, monthly average net profit is 2083 points, average profitable transaction is 1696 points, average loss transaction is 1095 points, profit per transaction is 215 points. With the rates perspective, the earning rate was 0.425 , the profitability rate was 1.80 and the profit rate was 1.35 .

In the study, an emotion-free investment method was evaluated on a 10-year dataset and explained with the results. In this sense, it was observed that by designing right algorithms and sustaining discipline without being affected by sudden price movements significantly contributed to profitability. However, it is thought that the trend-horizontal separation of the market will contribute to profitability in the algorithm design process. It is obvious that especially the algorithms that follow trend do not adapt to the market under horizontal market conditions. It will be correct to use algorithms that make trend tracking in the trend market situation by making trend-horizontal separation, and use intraday trading algorithms in horizontal market conditions. It will be correct to use algorithms that make trend tracking in the trend market situation by making trend-horizontal separation, and use intraday trading algorithms in horizontal market conditions. 
In addition to the algorithms created according to certain technical analysis principles, it is thought that the genetic algorithms created with machine learning principles, the processing algorithms to be created with artificial neural networks or fuzzy logic will better adapt to changing market conditions and will make significant contributions to profitability. In the optimization of the existing algorithms, it is thought that the optimization methods to be created with the principles of machine learning instead of the classical optimization methods will be more efficient in optimizing the algorithms. In this sense, it is thought that investment methods that are free from emotions are more profitable than conventional investment methods such as sensation and tips, whether in terms of classical algorithms or machine learning principles. This study will contribute to the limited literature in our country on algorithmic trading and will be encouraging to study the sub-disciplines of the subject such as machine learning and optimization.

Keywords: Algoritma, algorithmic trading, capital markets, technology, finance

Jel Codes: G17, O16

Öz: Teknolojinin hayatımızın her alanında kendisini yoğun bir şekilde hissettirdiği günümüzde sermaye piyasalarının da bu etkilenmeden uzak kalacağını düşünmek mümkün değildir. Bu anlamda özellikle geçtiğimiz on yıl göz önüne alındığında otomasyon ve yeni teknolojilerin kullanım alanlarının yadsınamayacak şekilde artmış olması sermaye piyasalarının da teknolojik olarak evrimleşmesine yol açmıştır. Teknolojik gelişmeler yatırım kararlarının alınmasında gerek bireysel yatırımcılar için gerek kurumsal yatırımcılar için gerekse sektör profosyonelleri için birçok yeniliği ve değişikliği içinde barındırmaktadır. Bu gelişmeler ışı̆̆ında günümüz sermaye piyasalarında alım-satım işlemlerinin büyük çoğunluğu algoritmalar vasıtası ile yapılmaktadır. Finansal enstrümanların fiyat değişimlerine etki eden etkenlerin çeşitlenmesi, piyasa koşullarının karmaşıklaşması, piyasaların geçmişe nazaran daha az karlı olması ve en önemlisi gelişen ve çeşitlenen iletişim imkânları nedeniyle piyasa hareketlerinin hızlanması ve bu hız etkeninin çoğu tahmini geride bırakması sermaye piyasalarında algoritma kullanmayı ihtiyaç haline getirmiştir. Gerek klasik teknik analiz yöntemlerine göre oluşturulmuş algoritmalar gerekse de son dönemde artan yapay zekâ yöntemleri ile oluşturulmuş algoritmalar olsun tüm bunların para hareketlerine yön vermede ağırlığının arttığı görülmektedir. Sermaye piyasalarındaki bu gelişim yatırımcılar için birçok firsat sunduğu gibi aynı zamanda içerisinde birçok tehdit de barındırmaktadır. $\mathrm{Bu}$ araştırma gelişmiş piyasalarda uzun yıllardır kullanılmakta olan ancak ülkemizde son zamanlarda sermaye piyasasının gündemine giren ve yatırımcılar için büyük bir ilgi alanı olan algoritmalar konusunda genel bir değerlendirme yaparak bakış açısı kazandırmayı amaçlamaktadır.

Anahtar Kelimeler: Algoritma, algoritmik işlem, sermaye piyasaları, teknoloji, finans

Jel Kodları: G17, O16

\section{Giriş}

Algoritma ilk olarak Türkistanlı alim Ebu Muhammed bin Musa el Harezmi’nin “Hisab elcebir" ve "El muhabala" kitaplarında geçen bir kavramdır ve El Harezmi’nin Latince okunuşudur (Balık, 2003: 8). Algoritma, bir sorunun çözümü için gerekli olan sıralı mantıksal adımların tümüdür (Tungut, 2017: 5). Bir problemin çözümünde izlenecek yol anlamına gelen algoritma; matematik ve programlamada bir problemi çözümlemek veya bir işi yapmak için tanımlanan, başlangıcı ve sonu belirlenen adımlardır.

Temelde algoritmalar, bilgisayarların karar verme matematiğidir ve hayatımızın hemen her alanında kullanılmakta, hayatımızı şekillendirmekte ve kolaylaştırmaktadır. Üretimden pazarlamaya, iletişimden sağlığa, eğitimden finansa kadar her alanda kullanıcılara hizmet etmektedirler.

\subsection{Finans ve Algoritma}

Algoritmik işlem, finansal olarak alım satım işlemlerinin bilgisayar uygulamaları vasıtası ile piyasaya iletilmesini ifade eder (Chan, 2009: 1). Otomatik yatırım, robo trading, algorithmic trading veya black box trading gibi isimlerle de anılır. Finansal piyasalar için yeni ve özel bir disiplindir (Kissell, 2014: 1; Kim, 2007: 8). 
Yatırımcıların algoritmalar yoluyla yatırım yapmak için öncelikle yatırım yapacakları enstrümanı ve algoritmalarının al-sat-tut yöntemlerini matematiksel talimatlar haline getirmeleri gerekir. Alım satım yöntemleri matematiksel ifadeler halinde bilgisayar uygulaması haline getirildikten sonra algoritma talimatları takip ederek bunları piyasada uygular (Durenard, 2013: 3).

Fon yöneticileri ve yatırımcılar algoritmaları çeşitli şekillerde kullanabilirler. Yatırımcılar algoritmaları riskten korunma (hedge) amaçlı kullanabileceği gibi arbitraj firsatlarını değerlendirmek için veya spekülasyon amaçlı da kullanabilirler.

\subsection{Algoritma Kullanmanın Başlıca Avantajları}

Algoritmik işlemlerin toplam hacimdeki payı her yıl artmakta ve modern finans sisteminin önemli bir parçası haline gelmektedir (Savaş, 2017: 2). Algoritmik işlemlerin, kullanıcılara sağladığ 1 avantajlar aşağıda ifade edilmiştir (Kim, 2007: 57; Kissell, 2014: 3).

- Yatırımciların özgün olarak kendi alım-satım stratejilerini duygusal enformasyona maruz kalmadan işlemesini sağlar.

- İnsan işlemlerine göre önemli derecede bir hız sağlar.

olunur.

- Emirlerin broker aracılığıyla verilmemesi nedeniyle bilgi sızıntılarının önüne geçmiş

- S1klıkla karşılaşılan insan hatalarının önüne geçilmesini sağlar.

- Yatırımcıları ekrana bağlı olmaktan kurtarır.

- Yatırımları önemli derecede disipline eder.

- Piyasada likidite oluşmasına katkıda bulunur.

- Büyük miktarlı emirlerin küçük parçalara ayrılarak alım-satımını kolaylaştırır.

\subsection{Algoritma Kullanmanın Başlıca Dezavantajları}

Algoritmik işlemler 2000'li yıllardan beri hızla gelişmektedir. Bu gelişim süreci bazı sakıncalar barındırmaktadır (Chan, 2009: 158; Kissell, 2014: 4). Bunlardan başlıcaları aşağıda ifade edilmiştir. olabilir.

- Aynı algoritmaların kullanılmasının piyasa bozucu bir duruma dönüşme ihtimali

- İyi kurgulanmamış ve test edilmemiş algoritmalar, ciddi zararlara sebep olabilir.

- Daha önce test edilmemiş ve beklenmeyen piyasa durumlarında algoritmaların nasıl tepki vereceğinin belirsiz olması ciddi zararlara sebep olabilir.

- Kullanılan algoritma, ortalama piyasa derinliği ile uyumsuz olabilir.

- Farklı algoritmalar, sert piyasa hareketlerinde birbirlerini tetikleyebilir. olabilir.

- Algoritmaların birbirleri ile çakışma olasılığı olağan dışı fiyat hareketlerine sebep

\section{Algoritmik İşlemlerin Gelişimi}

Piyasalardaki yatırımcı sayısının artması ve finansal enstrümanların fiyatlarını etkileyen faktörlerin daha karmaşık hale gelmesi finansal tahminlemeyi zorlaştırmış ve karlılığını azaltmıştır. (Kim, 2017: 1). Buna uyum sağlamak adına yatırımcılar ve fon yöneticileri algoritmik işleme yönelmişlerdir. Çünkü bilgisayarlar, büyük verileri daha verimli işleyebildiğinden ve karmaşık problemleri çok daha hızlı çözebildiklerinden piyasa değişimlerine daha hızlı tepki vermeyi 
sağlamaktadırlar. 2000'lerin başından 2005'e kadar toplam pazarın \%25'ini oluşturan algoritmalar, 2007 yılına geldiğimizde 3 kat artarak \%75 seviyesine ulaşmıştır (Kissell, 2014: 11). Günümüzde ise bu oranın daha da arttığı tahmin edilmektedir. Bu yönelim, algoritmik işlemlerin pazardaki hacminin artmasına neden olmuştur (Kim, 2007: 29).

Şekil 1: Algoritmik İşlemelerin Yıllar İtibarı İle Hacimsel Gelişimi

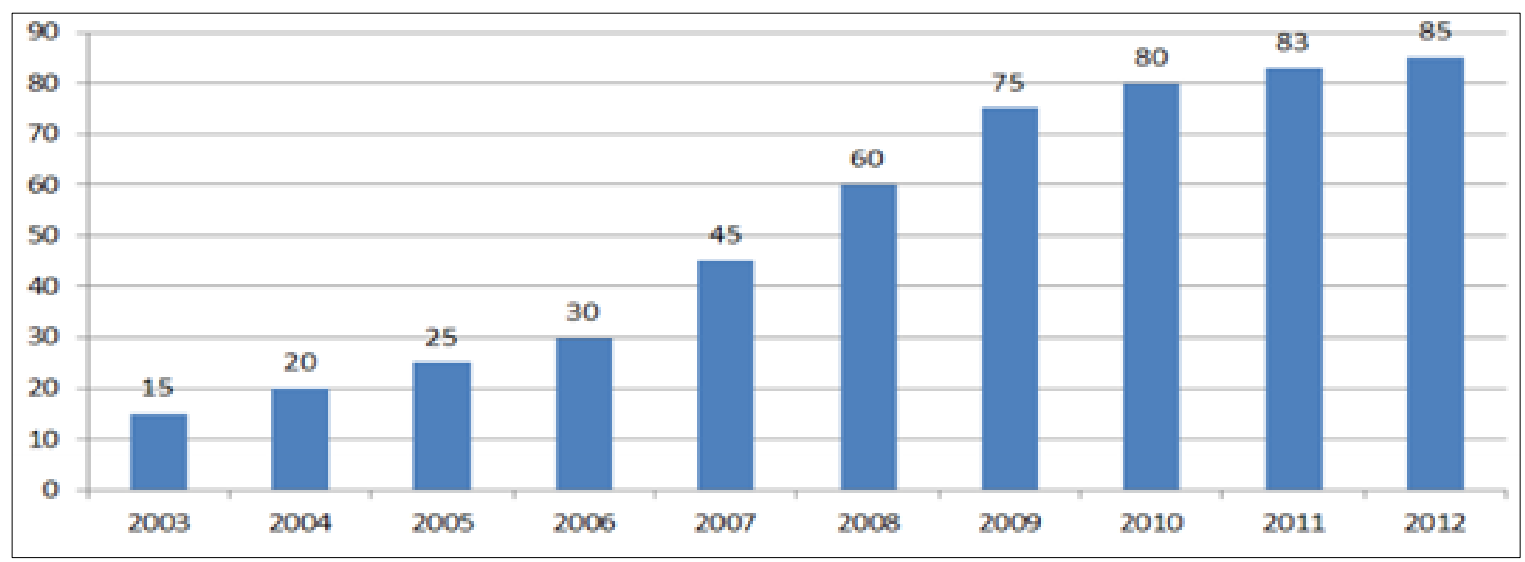

Kaynak: Glantz ve Kissell, 2003, s.258

1980'den beri algoritmik işlem stratejilerinin gelişimi hızla artmaktadır. Günümüzde ise finansal piyasalarda algoritmik işlem kullanımı kümülatif olarak her yıl \%10,3 oranında artmaktadır (Technavio's 2016 raporu: Global Algorithmic Trading Market, 2016-2020) Google trends aramalarında "algo trading" teriminin düzenli şekilde yükselmesi bu yeni alım satım disiplinine olan ilgiyi göstermesi açısından önemlidir.

Şekil 2: Yıllar Göre Goole Trends "Algo Trading" Aramalar1

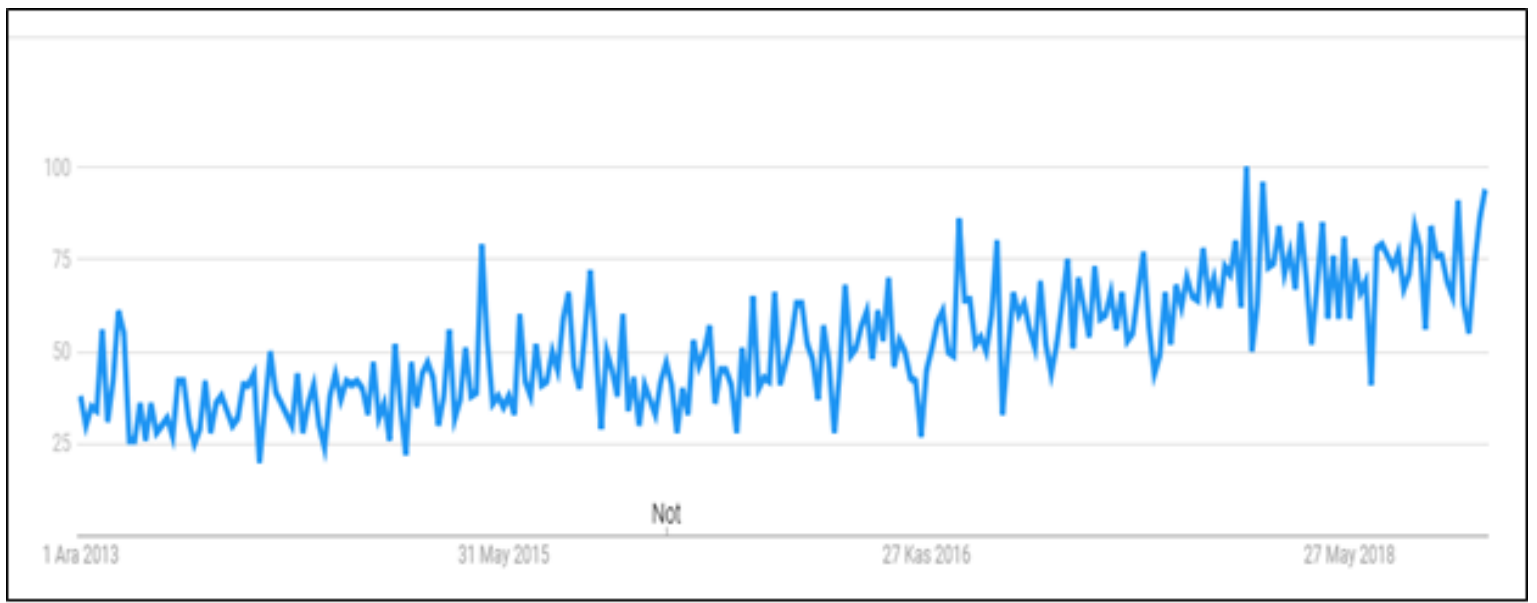

Kaynak: Google Stats

Bununla beraber algoritmalar son yıllarda tek seferde yapılan işlem miktarlarını küçültürken toplam işlem hacmini ise oldukça arttırmıştır. Buna örnek olarak NYSE'de 2000-2011 yılları arasındaki grafiği gösterebiliriz. Grafikten de görüldüğü gibi ortalama işlem miktarları düşerken buna paralel olarak işlem hacmi artmıştır. 
Şekil 3: Yıllar Göre Ortalama İşlem Büyüklüğü ve İşlem Hacmi Değişimi

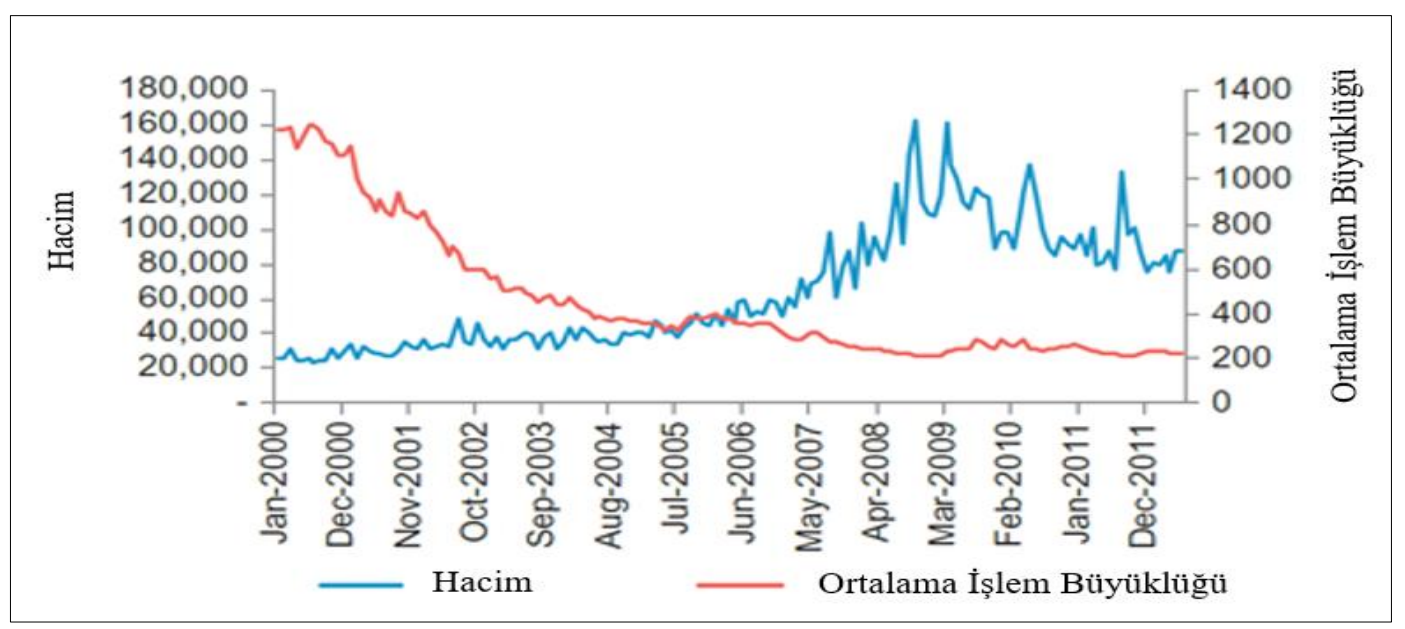

Kaynak: Kissell, 2014, s.9

\subsection{Algoritmaların Kullanımına Etki Eden Faktörler}

\subsubsection{Kolay Olmaları}

Kolaylık, programları kullanmak için önemli bir nedendir. Örneğin bir yatırımcı veya fon yöneticisinin 20 farklı enstrümanda işlem yapması oldukça zordur. Ancak önceden bir strateji oluşturulması durumunda algoritmalar kullanılarak 20 farklı enstrümana yönelik alım satımın iş yükü en aza indirilebilir.

\subsubsection{Karar Vermeyi Kolaylaştırması}

Algoritmik işlem programları otomatik emir iletmesinin yanında birçok yatırımeı ve fon yöneticisi için karar destek sistemi olarak duygusal enformasyona maruz kalmamak içinde destek alınan önemli kaynaktır.

\subsubsection{Hız}

Finansal piyasalarda algoritmaların kullanılmasına en önemli etkilerden birisi de hızdır. Emirlerin piyasaya iletilmesinde bir insana göre tartışılmaz şekilde üstünlük sağlar. Bu yönüyle karmaşıklaşan ve hızlanan piyasa hareketlerine uyum sağlamak için finansal piyasalarda algoritma kullanılması önemli bir avantajdır.

\subsubsection{Hataları Azaltması}

Yoğun iş temposunun olduğu zamanla yarışılan finansal piyasalarda insan hataları sıklıkla yaşanır. Bu hatalar genelde fiyat ve miktar hatalarıdır. Algoritmalar bu olası fiyat ve miktar hatalarının önüne geçmede verimli bir yardımcıdır.

\subsubsection{Uygun Maliyetlenme İmkanı}

Kimi zaman bir enstrümanı tek bir fiyattan almak yerine gün içerisinde zamana yayarak almak maliyetlenme açısından avantajlı bir durum olabilir. Algoritmik işlem programları, bu maliyetlenmeyi iş yükü yaratmadan gerçekleştirebilmesi nedeniyle önemli yardımcılardır.

\subsection{Türkiye'de Algoritmik Alım Satım}

Gelişmiş piyasalarda uzun yıllardır karar alma süreçlerinde kullanılan finansal algoritmalar son dönemde ülkemizde de yer edinmeye başlamışlardır ve tıpkı batıda olduğu gibi ülkemizde de algoritmik işlemlere olan eğilim her geçen gün artmaktadır. 
Türkiye'de kullanılan veri terminallerinin son yıllarda algoritmik işlem özelliklerine önem vermeleri ve bu yöne yatırım yaparak kullanım kolaylığı sunmaları algoritmik işlem kullanımının artarak devam edeceği hususunda ipucu vermektedir. Aracı kurumlarında bu alanda yeni personel istihdamı ve teknolojik altyapılarını güncellemeleri ve bu alanı yatırıma değer olarak görmeleri de bu yeni disiplinin önemini göstermektedir.

Ülkemizde algoritmik işlemler daha çok klasik teknik analize dayalı alım-satım algoritmalarından ve yüksek frekanslı alım-satım (HFT) işlemlerden oluşmaktadır. Bunun dışında arbitraj firsatlarını arayıp bu yönde işlem yapan algoritmalara da ilgi artııştır.

\section{Algoritmik İşlem Çeşitleri}

Finansal bir algoritma tasarlamanın belli adımları vardır. Bunlar; analiz, tasarım (dizayn), geriye dönük test (backtest), deneme ve uygulamadır. Tasarlanan algoritma, ilgili enstrümanın türüne göre analiz edilir. Analiz edilen enstrümana göre uygun bir algoritma oluşturularak al-sat-tut koşulları oluşturulur ve geçmiş performansı test edilir. Geçmişteki performans, gelecek için neler beklememiz gerektiğini ortaya koyar (Chan, 2013: 2). Test sonrasında deneme amaçl reel veya sanal piyasada test edilir. Test ve geçmiş verilerin çeşitli istatistiki testler sonucunda uygun olması durumunda algoritma uygulamaya konulur.

\subsection{Trend Takip Eden Algoritmalar}

Trend takibi yapan algoritmalar genellikle klasik teknik analiz prensiplerine göre fiyatların ana yönünü tespit etmek amaçlı kullanılan algoritmalardır. Bu tip algoritmalarda RSI, MACD, Momentum, Bollinger, Parabolic Sar vs. gibi teknik göstergeler tek başlarına veya birbirleri ile kombinlenerek kullanılırlar. Teknik gösterge (indikatör) değerleri en iyilenerek (optimizasyon) veya kişisel tecrübeye dayalı olarak değiştirilerek farklılaştırılabilir. Bu tip algoritmalarda karar verici algoritmayı çalıştıracağı veri dönemini kendi risk algısına göre bir dakikadan aylığa kadar belirleyebilir.

Şekil 4: Trend Takip Eden Algoritmik Bir Alım Satım Stratejisi

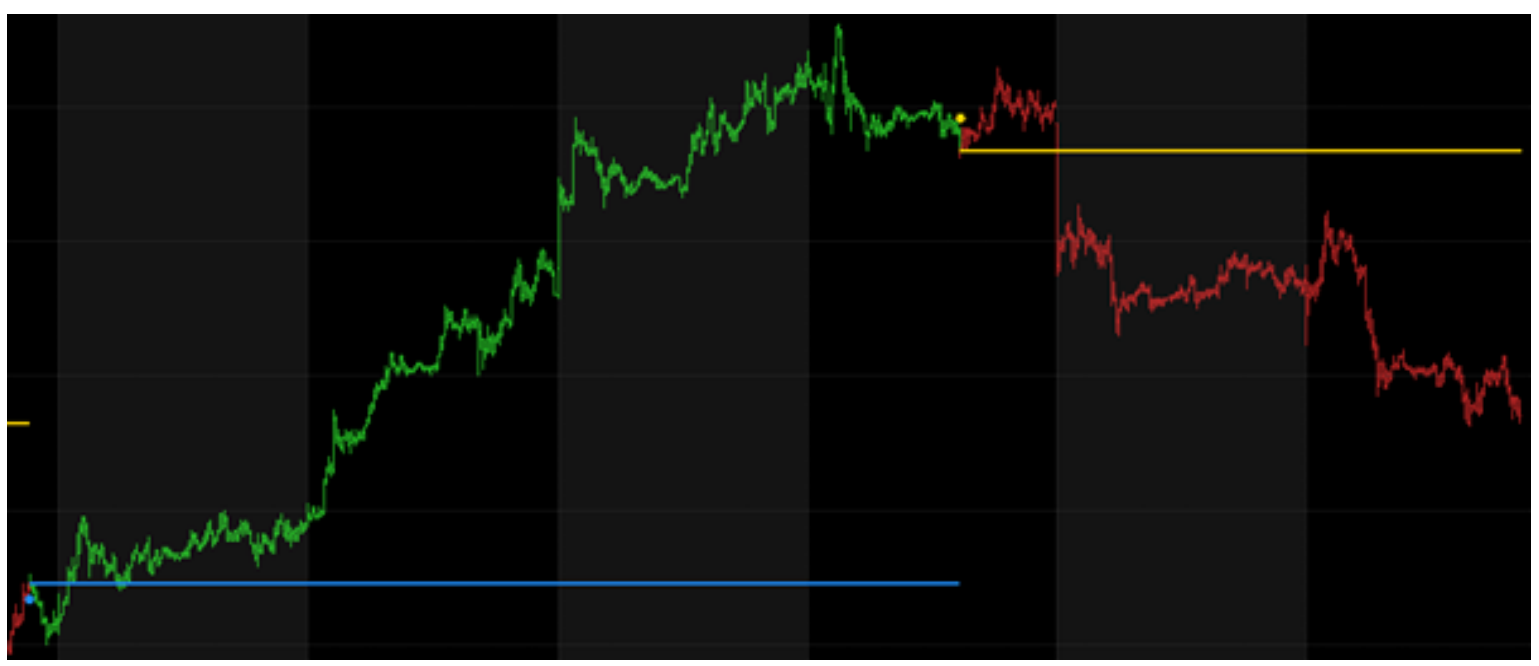

\subsection{Gün İçi İşlem Algoritmaları}

Piyasaların kapalı olduğu saatlerindeki gelişmelerden etkilenmek istemeyen yatırımcılar sadece piyasaların açık olduğu saatlerde işlem yapmayı tercih edebilirler. Böylece portföylerine müdahil olamayacakları saatlerdeki sabah boşlukları (GAP'leri), olumsuz haber akışı vb. gibi gelişmelerden etkilenmemeyi amaçlarlar. Bunun için algoritmalarına çalışma aralığ koyarlar ve algoritmalar bu kısıtlar dahilinde işlem yapar. Yatırımcılar bu tip algoritmalarda işlem 
saatleri dışındaki olumsuz gelişmelerden etkilenmediği gibi lehine olabilecek firsatlardan da yararlanmamış olurlar.

Şekil 5: Gün İçi İşlem Algoritması

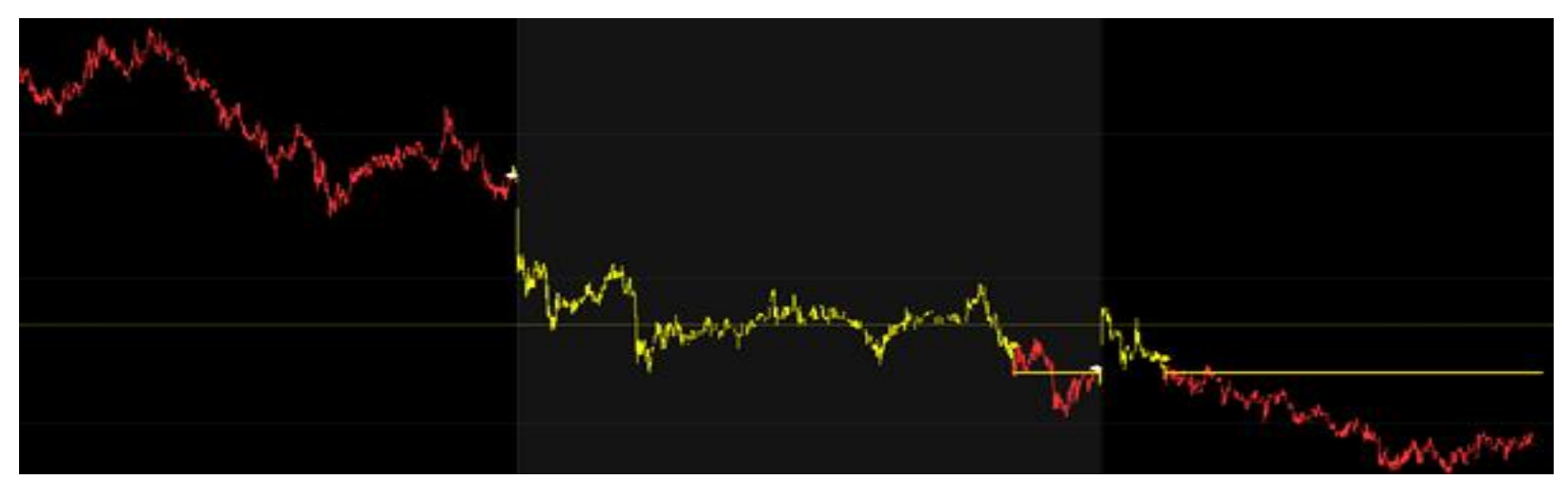

\subsection{Yüksek Frekanslı İşlemler (High-Frequency Trading)}

Algoritmik işlemlerin bir alt sınıfı olan yüksek frekanslı işlem (HFT) daha çok alım-satım emirlerinde hız faktörünün ön planda olmasını ifade eder. Yüksek frekanslı işlemlerde tanımlı algoritmalar milisaniyeler ile ölçülecek sürelerde hızla işlemleri yapabilirler. Genellikle piyasa yapıcılı̆̆ 1 , istatistiksel arbitraj firsatlarının yakalanması, likidite oluşturulması ve riskten korunma (hedge) için sıklıkla kullanılırlar (Donefer, 2010). Bu anlamda hızın ön plana çıktı̆̆1 istatistiksel arbitraj algoritmaları da ağırlıklı olarak yüksek frekanslı işlem kapsamında yapılmaktadır. Günümüzde yüksek frekanslı işlem kullanımının \%70'ler düzeyinde olduğu tahmin edilirken sadece spekülasyon amaçlı alım satım yüzdesinin ise $\% 25$ dolaylarında kaldığı düşünülmektedir (Kissell, 2014). Kısaca yüksek frekanslı işlemlerinin ağırlıklı olarak piyasa yapıcılığı ve riskten korunma (hedge) amaçlı kullanıldığını söyleyebiliriz.

Şekil 6: Kullanım Amacına Göre Yüksek Frekanslı İşlem Kullanımı

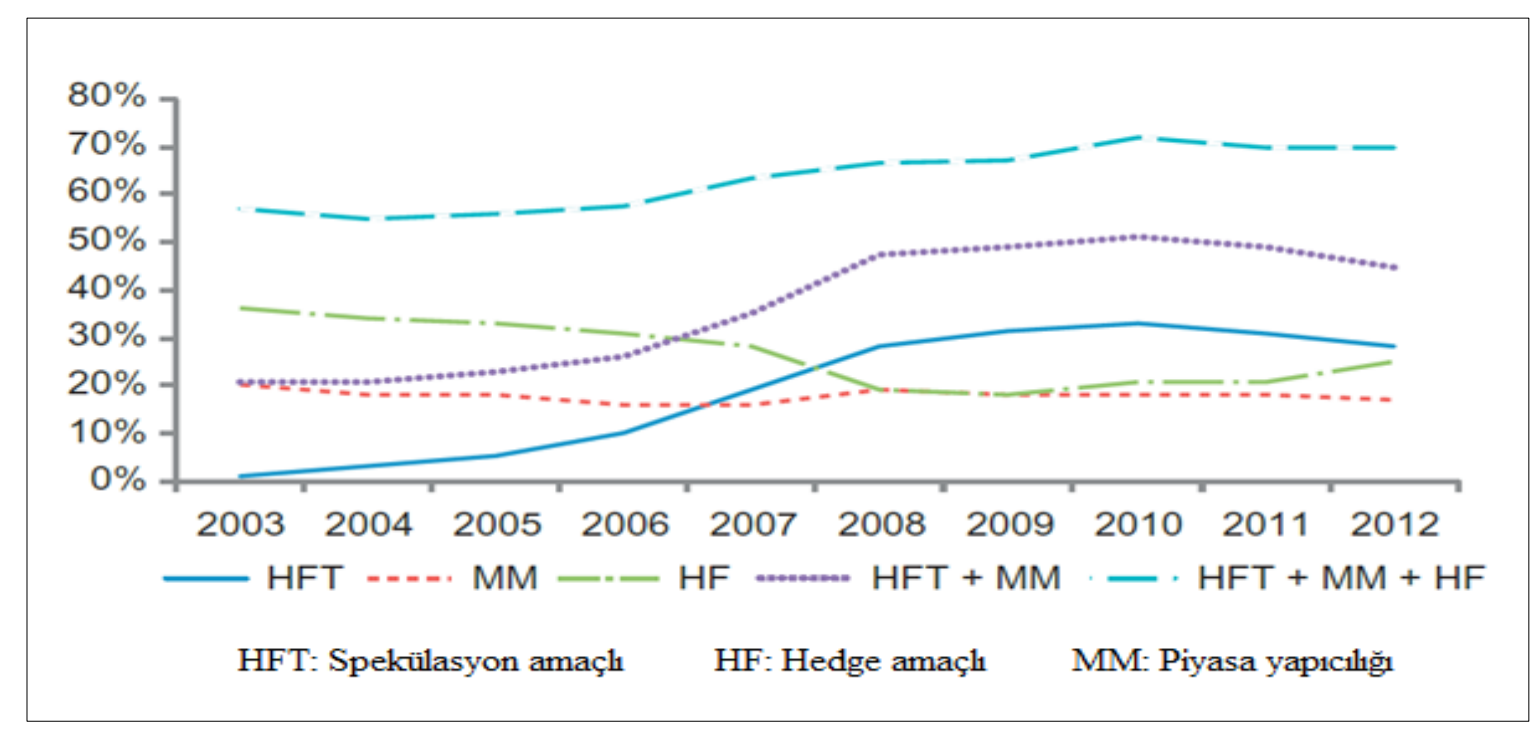

Kaynak: Kissell, 2014, s.14.

\section{4.İstatistiksel Alım Satım Algoritmaları}

Alım-satım algoritmaları oluşturulurken klasik teknik göstergeleri kullanılabilmektedir. İstatistiksel alım-satım algoritmalarında ise kullanılan materyal çeşitli istatistiki yöntemlerdir. 
Örneğin AR, MA ve ARIMA, ARCH ve GARCH gibi zaman serisine dayalı istatistiki modeller kullanılarak alım satım algoritması oluşturulabilir (Hsieh, Wang ve Lu, 2006). Bununla birlikte standart sapma, ortalamadan yüzde uzaklaşma, çeşitli vadelerdeki ortalamaların fiyat ve birbirleri ile ilişkisi gibi istatistiki yöntemlerde sıklıkla kullanılan istatistiki alım satım yöntemleridir.

\subsection{Yapay Zekâ Destekli Alım Satım Algoritmaları}

Yapay zekâ her alanda olduğu gibi finans sektöründe de önemini hissettirmektedir. Bilgi işlemsel zekâ yöntemleri, geleneksel istatistiki yöntemleri yetersiz kılacak karmaşık problemleri çözmeye çalışan ve doğadan esinlenen hesaplama yöntemleridir (Chen vd., 2007). Bu anlamda klasik teknik göstergelere veya istatistik metotlara göre oluşturulan algoritmaların yerini yapay zekâ tekniklerine göre oluşturulan algoritmalar almaya başlamıştır. Örneğin değer ve girdi en iyilemede (optimizasyon) genetik algoritmaların, öğrenmede ise yapay sinir ağlarının kullanılması ile destek vektör makineleri ve bulanık tabanlı ağ çıkarım sistemleri son dönemin algoritmik alım-satım konusunda önemli bir yer almaktadır.

\subsection{Sosyal Medya Algoritmaları}

Sosyal medya algoritmaları, Facebook, Twitter ve Linkedin gibi gelişen sosyal platformlardan yararlanarak alım-satım koşullarının oluşturulmasını ifade eder. Tasarlayıcılar sosyal medyadaki anahtar kelimeleri al-sat-tut şeklinde anlamlandırarak genel eğilimi tahmin etmeye çalışırlar. Erasmus Üniversitesi, Roterdam İşletme Fakültesi'nden araştırmacıları Li, Dalen ve Ress (2018), Twitter'dan analiz yaparak yön tahmininde oluşan bir algoritma geliştirmişlerdir. Araştırmacılar, "satın al" tavsiyelerinin yoğun bulunduğu dönemde yüksek getiri sağlandığını ve enstrümanların alım satımında önemli bir güce sahip olduğunu tespit etmişlerdir (Li, Dalen ve Ress, 2018). Bir başka çalışmada ise Dow Jones Borsası Endüstri Endeksi ile Twitter'daki paylaşımların \%87,6 oranda örtüştüğü tespit edilmiştir (Bollen, Mao ve Zeng, 2011).

\section{4.Örnek Strateji Oluşturulması ve Test Edilmesi}

$\mathrm{Bu}$ bölümde, algoritmik işlem çeşitleri kısmında belirtilen analiz, tasarım ve geriye dönük test (backtest) aşamaları takip edilerek, Direct FN Ideal veri terminali aracılığı ile örnek bir strateji oluşturulmuş ve test edilmiştir.

\subsection{Analiz}

Çalışmamızda örnek olarak, Borsa İstanbul Vadeli İşlemler ve Opsiyon Borsasında işlem gören VIOP30 yakın vade kontratı tercih edilmiştir. Bu enstrümanın seçilmesinde derinlik ve işlem hacminin yüksek olmasının yanı sıra Borsa İstanbul'un ana trend ürünü olması etkili olmuştur.

\subsection{Tasarmm}

VİOP30 ürününde kullanılacak algoritmanın trend takip eden ve klasik teknik analiz metotlarına göre oluşturulmuş bir algoritma olması tercih edilmiștir. Ayrıca örnek algoritmada "kar al" ve "stop" koşulu kullanılmamış; alış ve satış sinyalleri birbirinin simetriği olacak şekilde ve 5 dakikalık grafik periyodunda tasarlanmıştır.

Örnek stratejide girdi olarak 5 dakikalık veri vadelerinin yüksek, düşük ve kapanış fiyatları ile beraber Alligator göstergeleri, Parabolic SAR, Aroon Oscilattor ve 10 vadelik yüksek ve düşük fiyatlar kullanılmıştır.

Alım koşulu olarak;

- $\quad$ Her Alligator göstergesinin bir ve iki vade önceki seviyesinden büyük olmas1,

- Vade kapanışlarının Parabolic SAR değerinden büyük olması,

- $\quad$ Son vadenin en yüksek fiyatının son on vadenin en yüksek fiyatının bir önceki yükseğinden büyük olması, 
- $\quad 28$ değerli Aroon Oscillator göstergesinin 50 vadelik basit ortalamasının 0'dan büyük olması uygun görülmüştür.

Satım koşulu olarak;

- Her Alligator göstergesinin bir ve iki vade önceki seviyesinden küçük olmas1,

- Vade kapanışlarının Parabolic SAR değerinden küçük olması,

- $\quad$ Son vadenin en düşük fiyatının son on vadenin en düşük fiyatının bir önceki düşüğünden küçük olması,

- $\quad 28$ değerli Aroon Oscillator göstergesinin 50 vadelik basit ortalamasının 0'dan küçük olmas1 uygun görülmüştür.

\subsection{Backtest (Geriye Dönük Test)}

Tablo 1: Aylara Göre Kar/Zarar

\begin{tabular}{|l|r|r|r|r|r|r|r|r|r|r|r|r|}
\hline & OCAK & ŞUBAT & MART & NISAN & MAYIS & HAZIRAN & TEMMUZ & AĞUSTOS & EYLÜL & EKIM & KASIM & ARALIK \\
\hline $\mathbf{2 0 1 0}$ & -1870 & 6255 & 2950 & 5635 & 9200 & 5725 & -3840 & -3935 & 2945 & 2995 & 875 & -3540 \\
\hline $\mathbf{2 0 1 1}$ & -7390 & 4695 & -3395 & 3195 & -7040 & -2800 & 140 & 8090 & -2780 & -7130 & 11335 & 3290 \\
\hline $\mathbf{2 0 1 2}$ & -710 & -2995 & -2215 & 2320 & 4055 & -1475 & 3345 & 4935 & -3805 & 1855 & -1955 & 2875 \\
\hline $\mathbf{2 0 1 3}$ & 2430 & 9215 & -2910 & 1510 & 1980 & -1075 & -2690 & 5510 & 9450 & 2090 & 8250 & -10030 \\
\hline $\mathbf{2 0 1 4}$ & 95 & -1790 & 5120 & 7685 & 830 & -4500 & -1330 & -1610 & 2595 & -1830 & 2355 & 9115 \\
\hline $\mathbf{2 0 1 5}$ & 3150 & 6685 & 635 & 585 & 2300 & 845 & -6960 & -6890 & 2990 & 8200 & 7955 & 1315 \\
\hline $\mathbf{2 0 1 6}$ & 3295 & -4955 & -9045 & 915 & 875 & -2545 & 10400 & 2435 & -865 & -1470 & 4975 & 3810 \\
\hline $\mathbf{2 0 1 7}$ & 10015 & -1455 & -1290 & 4055 & -4460 & -2185 & 7955 & 7000 & 7970 & 9880 & -2490 & 9480 \\
\hline $\mathbf{2 0 1 8}$ & 4105 & -6480 & 9475 & 960 & -16145 & 2670 & 4065 & 12610 & -1240 & 12955 & -12225 & -9220 \\
\hline $\mathbf{2 0 1 9}$ & 9190 & 1045 & 15765 & 1855 & -9395 & 9730 & -3165 & 10100 & 1845 & -5460 & -7690 & -50 \\
\hline
\end{tabular}

Oluşturulan algoritma 01.01.2010 ile 31.12.2019 yılları arasında 120 ayda ve 5 dakikalık veri vadeleri üzerinde geriye dönük test edilmiştir.

Tablo 2: Oluşturulan Algoritmanın Genel İstatistikleri

\begin{tabular}{|l|r|}
\hline Toplam Getiri & 250.050 \\
\hline \% Getiri & 250.05 \\
\hline Toplam Ișlem Sayısı & 1162 \\
\hline Karı İșlem Sayısı $\%$ & 42.00 \\
\hline Kazandıran İșlem Sayısı & 494 \\
\hline Kaybettiren İșlem Sayısı & 660 \\
\hline Kazandıran Toplam & 973.000 \\
\hline Kaybettiren Toplam & -722.950 \\
\hline Net Kar & 250.050 \\
\hline Profit Factor & 1.35 \\
\hline
\end{tabular}

\begin{tabular}{|l|r|}
\hline En Būyūk Kar & 12.425 \\
\hline En Būyūk Zarar & -5.025 \\
\hline Ardıșık Kar Sayııı & 9 \\
\hline Ardışık Kar Miktaıı & 20.850 \\
\hline Ardıșı Zarar Sayısı & 12 \\
\hline Ardıșı Zarar Miktarı & -22.300 \\
\hline Alım İșlemi Sayııı & 581 \\
\hline Alım İșlemi Yūzdesi & 50.00 \\
\hline Satım İșlemi Sayısı & 581 \\
\hline Satım İșlemi Yūzdesi & 50.00 \\
\hline
\end{tabular}

Tablo 2'de görüldüğg̈ gibi 01.01.2010 ile 31.12.2019 yılları arasında toplam 1162 işlem yapılmış olup; işlemlerin 494 tanesi karlı, 660 tanesi ise zararlı sonuçlanarak brüt 250.050 puan kar elde edilmiştir. Net kar hesabında her işlem için 10 puan komisyon ile 25 puan kayma (slipaj) brüt kardan düşülerek 168.710 puan net kar hesaplanmıştır. Bu anlamda ayların \%62'si karlı olarak sonuçlanmıştır. Geriye dönük testte algoritmanın değerlendirilmesi için önemli bazı değerlerin açıklaması ve örnek stratejiye ilişkin sonuçlar aşağıda paylaşılmıştır. 


\subsubsection{Aylık Ortalama Net Kar}

Test döneminde algoritmanın net karının o dönem içerisindeki ay sayısına bölünmesi ile elde edilir. Aylık ortalama net kar değerinin olabildiğince yüksek olması tercih edilir. Örnek algoritmamızda aylık ortalama net kar 2083 puan olarak gerçekleşmiştir.

\subsubsection{Kazanma Oranı}

Kazanan işlem sayısının toplam işlem sayısına bölünmesi ile elde edilir. Kazanma oranının 0,50 üzerinde olması tercih edilir. Örnek algoritmamızda 0,425 olarak gerçekleşmiştir.

\subsubsection{Karlı İşlem Ortalaması}

Kazançlı işlem toplamının kazançlı işlem sayısına bölünmesi ile elde edilir. Olabildiğince yüksek olması tercih edilir. Örnek algoritmamızda 1696 puan olarak gerçekleşmiştir.

\subsubsection{Zararı İş̧lem Ortalaması}

Zararlı işlem toplamının zararlı işlem sayısına bölünmesi ile elde edilir. Olabildiğince düşük olması tercih edilir. Örnek algoritmamızda 1095 puan olarak gerçekleşmiştir.

\subsubsection{Karlıık Oranı}

Karlı işlem ortalamasının zararlı işlem ortalamasına bölünmesi ile bulunur. Karlılık oranının 1'den büyük olması tercih edilir. Örnek algoritmamızda 1,80 olarak hesaplanmıştır.

\subsection{6.İşlem Başına Kar}

Toplam net karın toplam işlem sayısına bölünmesi ile elde edilir. İşlem başına karın olabildiğince yüksek olması tercih edilir. Örnek algoritmamızda 215 puan olarak hesaplanmıştır.

\subsubsection{Kar Oranı (Profit Factor)}

Toplam karın toplam zarar bölünmesi ile elde edilir. Kar oranının büyük olması algoritmanın istikrarlı olduğunu gösteren önemli bir orandır. Genellikle 1,50 üzerinde olması tercih edilir. Örnek algoritmamızda 1,35 olarak hesaplanmıştır.

\section{Sonuç}

Algoritmalar artık finans dünyasının ayrılmaz bir parçası haline gelmiştir. Son yıllarda gerek likidasyonu arttırmada gerek duygulardan arındırılmış olarak yatırım yapmayı mümkün hale getirmede, gerekse yatırım yapmayı kolaylaştırmada önemli bir araç haline gelmişlerdir (Durenard, 2013: 19; Kim, 2007: 33; Savaş, 2017: 2). Bu açıdan finans dünyamızda son zamanlarda hızla yükselen bu yeni yatırım disiplininin geliştirilmesi için özellikle ülkemizde daha çok araştırmaya ihtiyaç vardır.

Bu çalışmada algoritmik işlemlerin özellikle yatırımları duygudan arındırma ve yatırımcıya disiplin kazandırma özelliklerine vurgu yapılmıştır. Doğru algoritmalar tasarlanarak, hem ani fiyat hareketlerinde zarar görmenin önüne geçilebilir hem de negatif psikolojik etkilerden korunmuş olunabilir. Bununla birlikte trend takibi yapan algoritmalar kullanılarak gün içi küçük fiyat dalgalanmalarından etkilenmeden ana trendler yönünde işlemler yapılabilir. Gece riski almak istemeyen yatırımcılar ise gün içi işlem algoritmaları ile piyasaların kapalı olduğu saatlerdeki gelişmelerden korunabilirler.

Büyük fonlar yönünden ise HFT imkânları kullanılarak arbitraj firsatları değerlendirilebilir ya da büyük miktarlı işlemler küçük parçalara bölünerek hızlı bir şekilde istenen işlemler gerçekleştirilebilir. Geliştiriciler açısından ise yapay zekâ tekniklerinin öğrenme yeteneği kullanılarak finansal piyasalar için öğrenen algoritmalar geliştirilerek, rasyonalitenin artmas1 sağlanabilir. Bununla birlikte borsalar ve aracı kurumların da bu alandaki altyapılarını güçlendirerek, 
kullanıcıların ihtiyaçlarına cevap verebilir hale gelmeleri algoritmik işlemlerin gelişmesi ve verimli kullanılabilmesi açısından oldukça önemlidir.

\section{Kaynakça}

Balık, H.H. (2013). “C” ile programlamaya giriş. FÜ Basımevi: Elazı̆̆.

Chan, E. (2009). Quantitative trading: how to build your own algorithmic trading business. Chichester, UK: John Wiley \& Sons Ltd.

Chan, E. (2009). Algorithmic Trading. New Jersey: John Wiley \& Sons.

Chen, James. (2010). Essentials of Technical Analysis for Financal Markets. New Jersey: John Wiley \& Sons.

Donefer, S.B. (2010). Algos gone wild: Risk in the world of automated trading strategies. The Journal of Trading Spring, 5 (2), 31-34.

Durenard, E. (2013). Professional automated trading: theory and practice. New Jersey: John Wiley $\&$ Sons.

Fenton -O’Creevy, M., Soane, E., Nicholson, N., \& Willman, P. (2011). Thinking, feeling and deciding: The influence of emotions on the decision making and performance of traders, Journal of Organizational Behavior, 32(8), 1044-1061.

Glantz, M., Kissell, R. (2013). Multi-asset risk modeling: Techniques for a global economy in an electronic and algorithmic trading era. San Diego, CA: Academic Press.

Hsieh, M.F., Wang, R.T. ve Lu, I.C. (2006). Applying Grey Relation Analysis To Establish The Financial Distress Prediction Model for Electronic in Taiwan, JCIS, http://www.atlantispress.com

Kim, K. (2007). Electronic and algorithmic trading technology. San Diego, CA: Academic Press.

Kissell, R. (2014). The science of algorithmic trading and portfolio management. San Diego, CA: Academic Press.

Li, T., van Dalen, J., van Rees, P.J. (2018). More than just noise? Examining the information content of stock microblogs on financial markets. Journal of Information Technology, 33(1), 50-69.

Savaş, M.C. (2017). Algorithmic trading strategies using dynamic mode decomposition: Applied to Turkish stock market. Unpublished master's thesis, Middle East Technical University, Ankara.

Tungut, H.B. (2017). Algoritma ve programlama mantı̆̆l. Kodlab Yayın Dağıtım: İstanbul.

https://trends.google.com.tr/trends/explore?date=today $\% 205-\mathrm{y} \& \mathrm{q}=$ algo $\% 20$ trading 